\title{
Low body fat and high cardiorespiratory fitness at the onset of the freshmen year may not protect against weight gain
}

\author{
Gabrielle Mifsud, Karine Duval and Éric Doucet* \\ School of Human Kinetics, University of Ottawa, Ottawa, Ontario, Canada K1N $6 N 5$ \\ (Received 28 January 2008 - Revised 21 July 2008 - Accepted 11 August 2008 - First published online 14 November 2008)
}

The purpose of this study was to examine the effects of pre-university adiposity and physical fitness on changes of body weight and adiposity during the freshmen year. Twenty-nine freshmen (sixteen females and thirteen males) completed the study. Body weight and composition (dual-energy X-ray absorptiometry), waist circumference (WC), energy intake ( $7 \mathrm{~d}$ food diary) and activity-related energy expenditure (accelerometry) were measured in September, December and at the end of March. Peak oxygen uptake $\left(\mathrm{V}_{\mathrm{O} \text { peak }}\right)$ was assessed at baseline only. Significant increases in body weight (1.9 (SD 2.0) kg, $P<0.05$ ), BMI (0.6 (SD 0.7$) \mathrm{kg} / \mathrm{m}^{2}, P<0.05$ ), WC (2.7 (SD 3.0) $\left.\mathrm{cm}, P<0.05\right)$ and $\%$ body fat (BF) (3.1 (SD 2.3$) \%, P<0.01$ ) were noted in males, especially over the course of the first semester. No significant changes were observed in females. Results from correlation analyses showed that, baseline $\% \mathrm{BF}$ was negatively associated with changes in body weight $(r-0.53, P<0.01)$ and $\% \mathrm{BF}$ $(r-0.41, P<0.05)$ over the academic year. Baseline \%BF predicted $27 \%(P<0.05)$ of the change in weight. Alcohol intake explained $34 \%$ $(P<0.01)$ and $17 \%(P<0.05)$ of the changes in $\mathrm{WC}$ and \%BF, respectively. The change in body weight and \%BF were also positively associated with baseline $\mathrm{V}_{\text {O2peak }}(r 0.51, P<0.01 ; r 0.48, P<0.01$, respectively) while dietary restraint was negatively related to the changes in $\% \mathrm{BF}$ $(r-0.43, P<0.05)$. In summary, lower pre-university adiposity, higher $\mathrm{V}_{\mathrm{O} \text { 2peak }}$ and higher alcohol intake are associated with greater changes in adiposity and body weight during the freshmen year.

Freshmen: Body composition: Adiposity: Physical activity: Alcohol

University students are believed to be likely to gain $6.8 \mathrm{~kg}$ (15 pounds) in their freshmen year (the 'Freshmen 15'). In reality, the freshmen weight gain has been reported to vary from $1 \cdot 1^{(1)}$ to $2.5 \mathrm{~kg}^{(2)}$, with a a great proportion of the weight gain occurring over the first semester $(1.4-1.9 \mathrm{~kg})^{(3,4)}$, whilst no sex differences in the changes in body weight have been reported $^{(2,4-7)}$. The evaluation of body composition performed in some of these studies, using either bioelectrical impedance analysis $^{(3,7)}$ or dual-energy X-ray absorptiometry ${ }^{(8)}$, also revealed an increase in percentage body fat $(\% \mathrm{BF})$, with one study reporting an increase in central adiposity over the freshmen year ${ }^{(8)}$.

Levitsky et al. ${ }^{(4)}$ found that weight gain was mostly associated with the consumption of high-fat foods (12\%), the number of evening snacks $(12 \%)$, and by eating at all-youcan-eat facilities for breakfast $(10 \%)$ and lunch $(10 \%)$. There is also evidence of a high prevalence of physical inactivity among university students ${ }^{(9-13)}$, but more relevant to the present study is the decrease in total physical activity ${ }^{(14)}$ and aerobic exercise during the first two years of university ${ }^{(2)}$. In fact, previous results support that individuals who display higher fat mass and lower physical activity level at the onset of the freshmen year, also gain more body weight during their first year ${ }^{(8)}$. However, to our knowledge no study has used direct measures of physical activity in order to determine the impact of the latter on the changes of adiposity that occur during the freshmen year.
Based on available literature and using precise assessments of adiposity and physical activity, we tested three hypotheses. We hypothesized that: (1) higher pre-university body weight and adiposity (dual-energy X-ray absorptiometry) would be associated with greater gains in body weight and adiposity over the freshmen year; and (2) that higher pre-university physical activity energy expenditure (accelerometry) and cardiorespiratory fitness $\left(\mathrm{V}_{\mathrm{O} 2 \max }\right)$ would be associated with lesser changes in adiposity over the freshmen year. We also hypothesized that changes in adiposity would be independent of sex. Finally, we explored possible predictors of changes in adiposity such as socio-demographic variables and eating behaviour (Three-Factor Eating Questionnaire).

\section{Methods \\ Participants \\ Thirty-three freshmen students were recruited from the University of Ottawa through advertisements (i.e. posters and mail) and from a stand set up at the University Center to inform students about the study. Four freshmen dropped out due to time constraints. Twenty-nine freshmen (sixteen females and thirteen males) thus completed the study. Their characteristics are presented in Table 1 . The freshmen were predominantly Caucasians ( $n$ 27), with two students classified}

Abbreviations: $\mathrm{V}_{\mathrm{O} \text { peak }}$, peak oxygen uptake; WC, waist circumference; \%BF, percentage body fat.

* Corresponding author: Dr Éric Doucet, fax +1 613562 5149, email edoucet@uottawa.ca 
as other ethnicity. Twelve were in the Faculty of Arts, ten in Social Sciences and seven in Health Sciences. Participants were included if they were 18 years or older, attending their first year at university, currently living in residence, previously lived at home, body weight did not vary more than $2 \mathrm{~kg}$ in the last 6 months, apparently healthy, non-smokers, not taking medications that could impact on energy intake and expenditure, did not diet during the previous 6 months, and were not pregnant or intending to become pregnant in the next 7 months. Those taking oral contraception were allowed to participate in the study on condition that they had been doing so for more than 6 months. We selected a sample of weight-stable participants to reduce the probability of observing changes in weight and adiposity that would have been due to factors other than the first-time exposure to the university environment. Ethical approval was granted by the University of Ottawa Research Ethics Committee and all participants gave their written consent.

\section{Design and procedure}

Participants were recruited on the university campus over a 2-week period in late August/early September 2006. At that time, participants met the researchers for one screening session on campus. Thereafter, participants visited the laboratory on three separate occasions, in the second and third week of September and the first 2 weeks of December 2006, and the last week of March and first week of April 2007. All three periods of testing lasted 2 weeks. Measurements were taken as early as possible in September and close to the Christmas break and the end of the second semester without overlapping with end-of-term examination periods. During the September session, participants filled out the Three-Factor Eating Questionnaire, and their weight and height, waist circumference (WC) and body composition were measured. A peak oxygen uptake $\left(\mathrm{V}_{\text {O2peak }}\right)$ test was also performed. The two subsequent testing sessions (December and April) included measures of body weight, WC and body composition. At the end of each of the three testing periods participants were instructed to complete a $7 \mathrm{~d}$ food diary and asked to concurrently wear an accelerometer for $7 \mathrm{~d}$. The same researcher performed the measurements at each of the three time-points.

\section{Anthropometric measures}

Body weight and height (BWB-800AS digital scale and HR-100 height rod; Tanita Corporation of America Inc.) were measured $2 \mathrm{~h}$ after a light meal while subjects wore a hospital gown. A conventional measuring tape abiding to Canadian Society for Exercise Physiology standards was used to measure WC. An average of two WC measurements was taken. Body composition was measured using dual-energy X-ray absorptiometry (Lunar Prodigy, GE Medical System). CV and correlation coefficient for $\% \mathrm{BF}$ measured in twelve subjects tested in our laboratory were $1.8 \%$ and $r 0.99$, respectively.

\section{Peak oxygen uptake measurement}

Participants were asked not to eat or have coffee for $2 \mathrm{~h}$ before the test, and not to consume alcoholic beverages or exercise for the $6 \mathrm{~h}$ before. A high ramped protocol with a consistent

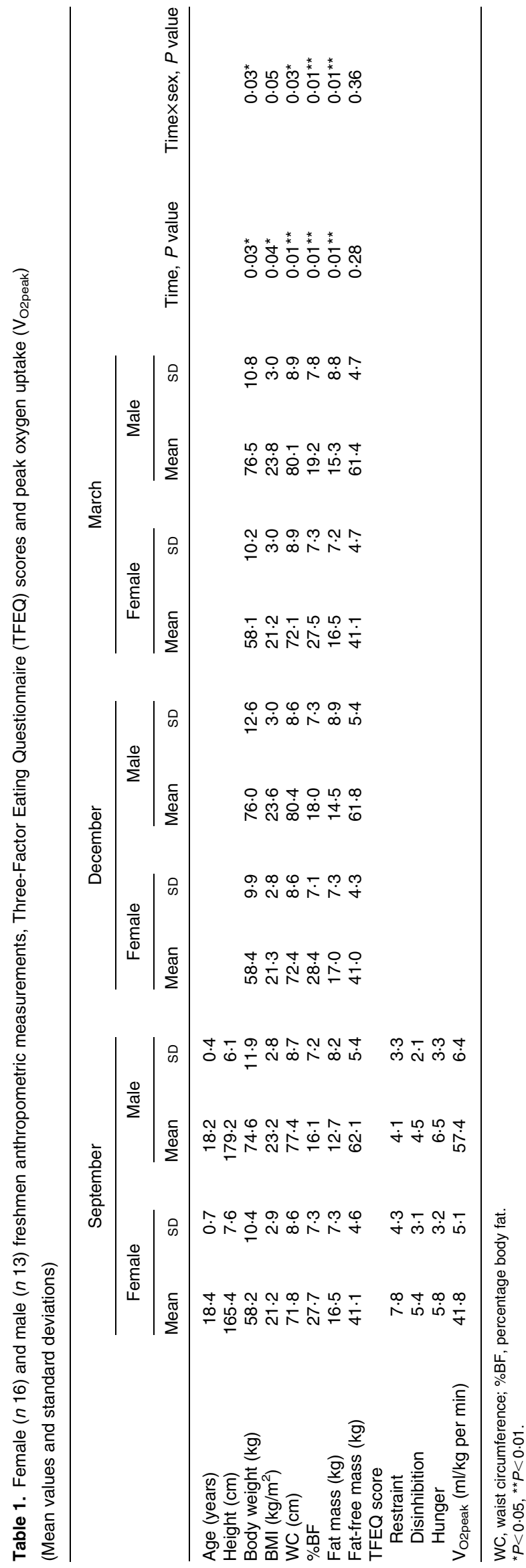


and continuous increase in speed and grade was used to measure $\mathrm{V}_{\mathrm{O} 2 \max }$. The initial speed was $2.6 \mathrm{~km} / \mathrm{h}$ at $5 \%$ gradient (3.3 metabolic equivalents). Speed and gradient progressively increased every 30,40 or $60 \mathrm{~s}$ to reach a maximum of $9.6 \mathrm{~km} / \mathrm{h}$ at $22 \%$ gradient (19.2 metabolic equivalents) by the twentyfifth stage $(15 \mathrm{~min})$. At least two of the following criteria were used to determine whether $\mathrm{V}_{\mathrm{O} 2 \max }$ was reached: (1) no further increase in oxygen uptake or an increase $\leq 150 \mathrm{ml} / \mathrm{min}$ with an increase in workload; (2) $\mathrm{RQ} \geqq 1 \cdot 1$; and (3) a heart rate equal to or greater than the predicted maximum heart rate (220 - age). Some subjects did not achieve a plateau of $\mathrm{O}_{2}$ consumption. For this reason, $\mathrm{V}_{\mathrm{O} \text { 2peak }}$ will be used henceforth. Analysers were calibrated before every test to further ensure the reliability of the measurement. This measurement was conducted during the September session only.

\section{Energy intake}

Average daily energy intake was measured using a $7 \mathrm{~d}$ food diary. Participants recorded all dietary intake including beverages and the respective quantity consumed. A guide sheet on portions for different foods and a sample diary for a day were attached with the food diary for guidance. Nutritional data were analysed using the computer program Food Processor SQL, V 9.6.2 (ESHS Research, Salem, OR, USA).

\section{Accelerometry}

Activity-related energy expenditure was examined using accelerometry (Actical-Mini Mitter Co. Inc., Bend, OR, USA). Participants wore the accelerometers upon waking up and took it off just before going to bed for a $7 \mathrm{~d}$ period. Such duration was chosen as it is estimated to result in $90 \%$ reliability for the measurement of physical activity in both males and females ${ }^{(15)}$. The accelerometer was worn at lower back level since this was evaluated as the best predictor of energy expenditure $(r 0.92-$ 0.97), compared to lower leg/foot, upper leg, head and trunk, lower $\mathrm{arm} / \mathrm{hand}$, and upper $\operatorname{arm}^{(16)}$.

\section{Socio-demographic questionnaire}

A socio-demographic questionnaire was used to collect information pertaining to the participants' place of residence prior to attending university residence (urban, rural or other), the type of residence they lived in (apartment style, shared room, etc.), the number of televisions available, their Faculty (Arts, Social Sciences or Health Sciences), as well as their income and their parents' income, and whether they subscribed to a university meal plan to eat at the cafeteria or not.

\section{Eating behaviour}

The Three-Factor Eating Questionnaire by Stunkard, Messick $^{(17)}$ was used to measure dietary restraint, disinhibition and hunger. This fifty-four-item questionnaire included thirty-six true/false questions and eighteen Likert-scale type questions. The validity of this questionnaire has been supported for both adolescents and adults ${ }^{(18,19)}$. The Three-Factor Eating Questionnaire was administered during the first session to obtain baseline scores.

\section{Data analysis}

All statistical analyses were performed using the Statistical Product and Service Solution software, version 11.5 (SPSS Inc., Chicago, IL, USA). For anthropometric measures as well as for activity-related energy expenditure and energy intake, the effect of time and time by sex interaction were examined using a 3 (time: September, December and March) $\times 2$ (sex: female and male) repeated measures ANOVA. Participants were included in these analyses if they completed all three measurements. Pearson correlations were performed between baseline variables and changes in anthropometric variables from September to December and then again for September to the end of March. To identify the best predictors of change, stepwise regression analyses included significant correlates of changes in dependent variables. Effects were considered significant at $P<0.05$ and data are presented as means and standard deviations.

\section{Results}

Thirty of the thirty-three freshmen recruited in September returned in December and twenty-nine in March. The descriptive statistics of subjects who completed the study are presented in Table 1. A significant sex by time interaction was observed for all anthropometric measures (Table 1). Over the first semester a significant increase in body weight $(1.4 \mathrm{~kg}, \quad P=0.05)$, WC $(2.9 \mathrm{~cm}, P<0.01), \% \mathrm{BF}(1.9 \%$, $P<0.01)$ and fat mass $(1.8 \mathrm{~kg}, P<0.01)$ was noted for men but not for women. Similarly, at the end of the academic year significant increases were observed for body weight $(1.9 \mathrm{~kg}, P<0.05)$, BMI $\left(0.6 \mathrm{~kg} / \mathrm{m}^{2}, P<0.05\right)$, WC $(2.7 \mathrm{~cm}$, $P<0.05)$, \%BF $(3.1 \%, P<0.01)$ and fat mass $(2.6 \mathrm{~kg}$, $P<0.01)$ in men.

No significant effect of time for daily energy expenditure, daily energy intake, macronutrient consumption and alcohol were observed for both males and females $(P>0.05$; Table 2). A significant sex by time interaction was identified only for the percentage of energy from protein consumed by the females during the first semester $(1.7 \%, P<0.05)$.

Associations between changes in body weight, $\mathrm{WC}, \% \mathrm{BF}$ and baseline measures were examined with correlation analyses. All subjects were pooled because of the small sample size. These results are presented in Table 3. During the first semester, changes in body weight and WC were associated with both baseline alcohol intake $(r 0.48, P=0.01$; $r 0.51, P<0.01$, respectively) and baseline $\mathrm{V}_{\text {O2peak }}(r 0.36$, $P=0.05 ; r 0.39, P=0.03$, respectively) (Table 3 ). Changes in WC were negatively correlated with baseline \% $\mathrm{BF}$ $(r-0 \cdot 38, P=0 \cdot 04)$. A positive association was also noted between changes in \% BF and baseline alcohol intake $(r 0.63$, $P<0 \cdot 01)$. Over the course of the academic year, the changes in body weight were significantly negatively correlated with baseline \%BF $(r-0.53, P<0 \cdot 01)$. In addition, baseline alcohol intake also remained positively correlated to the changes in WC $(r 0.45, P=0.02)$ and \%BF $(r 0.58, P<0.01)$. Changes in $\% \mathrm{BF}$ were also positively correlated with baseline $\mathrm{V}_{\mathrm{O} \text { peak }}$ $(r 0.48, P<0.01)$ and negatively correlated with baseline \% $\mathrm{BF}$ $(r-0.41, P=0.03)$. Dietary restraint showed a negative correlation with the change in $\mathrm{WC}$ and \% $\mathrm{BF}$ over the first semester ( $r-0.46, P=0.01 ; r-0.42, P=0.02 ; r-0.44, P=0.02$, 


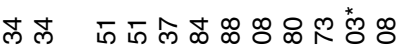
ó ó丶万人்

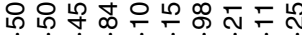
००

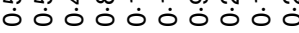

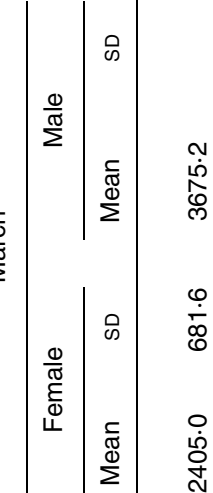

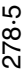

Nor

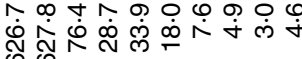
ले

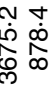

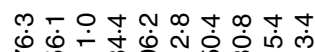
으

N t

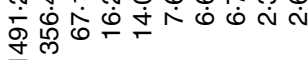

ب人

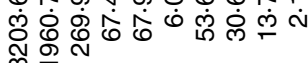
$\infty 0$ ํํㅇํํ

\section{守}

m 守各ம

人 OOONOOONGN

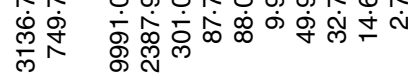

ก. +

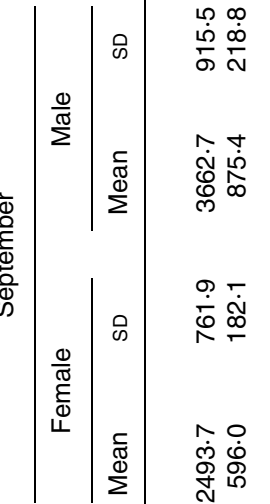
ஸ்

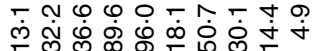
응 @्ల

non monmmo ஜ 는

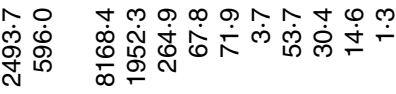

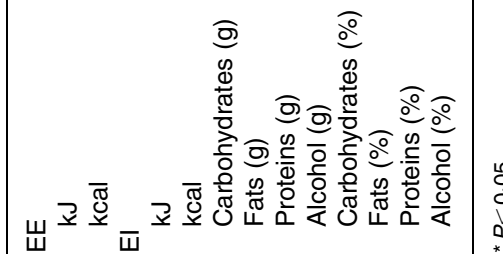

respectively), as well as for the change in $\% \mathrm{BF}$ over the full academic year $(r-0.43, P=0.02)$. Among our cohort, none of variables identified from the socio-demographic questionnaire were found to correlate with changes in body weight, WC and body fat.

To explore the best predictors of changes in adiposity, stepwise regression analyses were performed. Results presented in Table 4 show that, during the first semester, $44 \%$ of the variance in body weight changes was explained by baseline carbohydrate and alcohol intake $(P<0 \cdot 01)$. Baseline alcohol intake alone also explained $26 \%(P=0.01)$ and $40 \%$ $(P<0.01)$ of changes in $\mathrm{WC}$ and $\% \mathrm{BF}$, respectively. Over the full academic year, $27 \%$ of the variance in body weight changes was explained by baseline \%BF $(P=0.01)$. Alcohol alone explained $20 \%$ of the change in WC $(P=0.02)$. Baseline alcohol consumption explained $34 \%$ of the change in $\% \mathrm{BF}(P<0 \cdot 01)$.

\section{Discussion}

Similar to results from previous studies, we show a significant increase in body weight and adiposity over the freshmen year, most of which occurs during the first semester. Contrary to the three leading hypotheses of this paper, we also show (1) that higher pre-university adiposity levels were associated with lesser changes in adiposity; (2) that higher pre-university physical fitness levels $\left(\mathrm{V}_{\mathrm{O} 2 \text { peak }}\right)$ were associated with greater changes in adiposity; and that (3) men gained body weight and adiposity whereas women did not during the freshmen year. Similar to findings from other studies, pre-university alcohol intake was a consistent predictor of changes in adiposity over the freshmen year.

One of the interesting observations of the present study is that displaying lower adiposity and higher physical activity before the onset of the freshmen year may not necessarily be protective against increases in body weight and fat over the academic year. This contrasts with Morrow et al. ${ }^{(8)}$ who concluded that although normal-weight freshmen had gained body weight, those weighing more, having greater fat mass and being less active at baseline, gained more body weight during their first year. In the present study, freshmen with less \% BF experienced greater increases in body weight, $\mathrm{BMI}, \mathrm{WC}$ and $\% \mathrm{BF}$ than freshmen with more $\% \mathrm{BF}$ at the start of university. Baseline \%BF explained 27 and $26 \%$ of the change in body weight and BMI, respectively. If we assume that students who started university with higher levels of body fat were likely to consume more high-fat foods and to be more sedentary prior to university ${ }^{(20)}$, it could be speculated that the transition to an environment that promotes the consumption of energy-dense foods ${ }^{(4,21)}$ and low levels of physical activity ${ }^{(9,22-24)}$ would have had less impact on energy balance and ultimately on energy stores. Additional support for this argument comes from the observation that freshmen in the present study with higher baseline $\mathrm{V}_{\text {O2peak }}$ also tended be the ones in whom the greater changes in adiposity were noted. Hence, the resulting effect on energy balance would be expected to be greater for those freshmen who were more active before university (although this was not measured in the present study), and became relatively more sedentary as a result of the exposure to the university environment. The present findings should 
Table 3. Correlation of absolute changes in body weight, BMI, waist circumference (WC) and percentage body fat (\%BF) with baseline measures ( $P$ values)

\begin{tabular}{|c|c|c|c|c|c|c|c|c|}
\hline & \multicolumn{2}{|c|}{$\begin{array}{l}\text { Change in body weight } \\
\text { from September to }\end{array}$} & \multicolumn{2}{|c|}{$\begin{array}{l}\text { Change in BMI from } \\
\text { September to }\end{array}$} & \multicolumn{2}{|c|}{$\begin{array}{l}\text { Change in WC from } \\
\text { September to }\end{array}$} & \multicolumn{2}{|c|}{$\begin{array}{l}\text { Change in \%BF from } \\
\text { September to }\end{array}$} \\
\hline & December & March & December & March & December & March & December & March \\
\hline \multicolumn{9}{|l|}{ Anthropometry } \\
\hline Weight (kg) & 0.18 & -0.01 & 0.08 & -0.02 & 0.15 & 0.15 & 0.24 & 0.35 \\
\hline BMI $\left(\mathrm{kg} / \mathrm{m}^{2}\right)$ & 0.02 & -0.11 & -0.08 & -0.10 & 0.07 & 0.09 & 0.13 & 0.27 \\
\hline WC (cm) & 0.15 & -0.19 & 0.03 & -0.18 & 0.04 & -0.09 & 0.22 & 0.27 \\
\hline \multirow{2}{*}{\multicolumn{9}{|c|}{$\mathrm{El}$}} \\
\hline & & & & & & & & \\
\hline $\mathrm{kJ}$ & $0.47^{*}$ & 0.35 & 0.24 & 0.34 & 0.25 & 0.26 & 0.36 & $0.50^{*}$ \\
\hline Carbohydrates (g) & $0.51^{*}$ & 0.33 & 0.36 & 0.32 & 0.22 & 0.19 & 0.28 & 0.38 \\
\hline Fats $(\mathrm{g})$ & 0.20 & 0.07 & -0.03 & 0.08 & 0.08 & 0.07 & $0 \cdot 12$ & 0.25 \\
\hline Proteins (g) & 0.17 & 0.21 & -0.02 & 0.21 & 0.02 & 0.16 & 0.21 & 0.37 \\
\hline Alcohol $(\mathrm{g})$ & $0.48^{\star \star}$ & $0.49^{* *}$ & 0.38 & $0.45^{\star}$ & $0.51^{\star \star}$ & $0.45^{\star}$ & $0.63^{\star \star}$ & $0.58^{\star}$ \\
\hline $\mathrm{EE}(\mathrm{kJ})$ & 0.29 & 0.21 & 0.20 & 0.19 & $0.42^{*}$ & 0.18 & 0.26 & 0.19 \\
\hline $\begin{array}{l}\mathrm{V}_{\text {O2peak }}(\mathrm{ml} / \mathrm{kg} \text { per } \mathrm{min}) \\
\text { TFEQ score }\end{array}$ & $0.36^{*}$ & $0.51^{* *}$ & 0.21 & $0.48^{\star *}$ & $0.39^{*}$ & 0.36 & 0.35 & $0.48^{*}$ \\
\hline Restraint & -0.31 & -0.29 & -0.12 & -0.29 & $-0.46^{*}$ & -0.13 & $-0.42^{\star}$ & $-0.43^{*}$ \\
\hline
\end{tabular}

TFEQ, Three-Factor Eating Questionnaire; $V_{\text {O2peak }}$, peak oxygen uptake.

${ }^{*} P<0.05,{ }^{\star *} P<0.01$

nonetheless be weighed against study design limitations, such as sample size and the variability of methods such as accelerometry and energy intake.

The present results show that men experienced more significant changes for all anthropometric measures than did women. It has been reported that students who are aware of the 'Freshmen $15^{\prime}$ are concerned about gaining body weight, a concern more often expressed by female freshmen ${ }^{(6)}$. Women in the present study may thus have modified their physical activity and dietary practices throughout the year as a preventative measure against body weight gain. The observation that dietary restraint was negatively related to changes in body weight and composition in the present study and that women displayed higher dietary restraint scores than male subjects may also explain differences in body weight and adiposity over the academic year. It has been previously demonstrated that restrained eaters typically consume less energy than their less restrained counterparts ${ }^{(25,26)}$. In support of this, the present results also showed that freshmen with higher initial restraint (including both females and males) consumed significantly fewer $\mathrm{kJ}$ of energy and less alcohol per day at baseline. Considering the possible involvement of dietary restraint in mediating sex-related difference in freshmen weight gain, future studies should consider assessing this variable at all time-points.

To date only one study on the 'Freshmen 15' examined changes in WC, reporting an increase from 69.4 to $70.3 \mathrm{~cm}$ over a 7 -month period ${ }^{(8)}$. The increase in $\mathrm{WC}$ in the present study was more pronounced, with males showing a significant increase of $2.9 \mathrm{~cm}$ during the first semester and a total of $2.7 \mathrm{~cm}$ during the first year. Despite the fact that $\mathrm{WC}$ for both the females and males was below the National Institute of Health cut-off points of 88 and $102 \mathrm{~cm}$, respectively ${ }^{(27)}$, a linear relationship between $\mathrm{WC}$ and all-cause mortality was recently observed for males ${ }^{(28)}$. In fact, the analysis of studies of abdominal obesity and cardiovascular outcomes revealed that a $1 \mathrm{~cm}$ increase in WC was associated with a $2 \%$ increased risk for $\mathrm{CVD}^{(29)}$. Whether or not this increase does indeed represent cause for concern is beyond the scope of the present study.

As reported by the American College Health Association, $84.4 \%$ of university students consume alcohol ${ }^{(22)}$. Alcohol was positively correlated with all changes in anthropometric markers observed in this cohort. The consumption of alcohol seems to increase energy intake and promote little or no compensation for its energetic content, while inhibiting the

Table 4. Stepwise regression analysis examining predictors of changes in body weight, BMI, waist circumference (WC) and percentage body fat (\%BF) among freshmen ( $n$ 29)

\begin{tabular}{|c|c|c|c|c|}
\hline Dependent variable & Step no. & Predicting variable & $r^{2}$ & $P$ value \\
\hline \multicolumn{5}{|l|}{ September to December } \\
\hline \multirow[t]{2}{*}{ Change in body weight } & 1 & Carbohydrates (g) & 0.26 & 0.01 \\
\hline & 2 & Alcohol (g) & 0.44 & 0.01 \\
\hline Change in WC & 1 & Alcohol (g) & 0.26 & 0.01 \\
\hline Change in \%BF & 1 & Alcohol (g) & 0.40 & 0.01 \\
\hline \multicolumn{5}{|l|}{ September to March } \\
\hline Change in body weight & 1 & $\% \mathrm{BF}$ & 0.27 & 0.01 \\
\hline Change in $\mathrm{BMI}$ & 1 & $\% \mathrm{BF}$ & 0.26 & 0.01 \\
\hline Change in WC & 1 & Alcohol (g) & 0.20 & 0.02 \\
\hline Change in \%BF & 1 & Alcohol (g) & 0.34 & 0.01 \\
\hline
\end{tabular}


oxidation of other substrates, particularly fat ${ }^{(30)}$. Further, it would also seem that alcohol favours the storage of fat in the abdominal region ${ }^{(31)}$. Using $3 \mathrm{~d}$ diet records among 135 freshmen, Horwath ${ }^{(32)}$ reported that male freshmen obtained $3.7 \%$ of their daily energy from alcohol while this was $2.6 \%$ for their female counterparts. With the use of $7 \mathrm{~d}$ dietary records we found an equal percentage of energy obtained from alcohol for the males $(3.7 \%)$ and less for the females $(1.5 \%)$. Results from the present study reinforce the notion that the intake of alcohol may be an important contributor to increased energy intake and energy storage among freshmen students.

\section{Conclusion}

Previous observations, as well as results from the present study, show that freshmen body weight gain is less than the alleged $6.8 \mathrm{~kg}$ (15 pounds). Furthermore, the present study highlights the possibility that displaying lower adiposity and higher physical fitness at the onset of the university year may not be protective of increases in total and central adiposity over the course of the freshmen year. Further research involving both lean and overweight freshmen, as well as physically fit and unfit freshmen, will however be needed to confirm the findings of the present study.

\section{Acknowledgements}

É. D. is a recipient of a CIHR/Merck-Frosst New Investigator Award, a Canadian Foundation for Innovation New Opportunities Award and an Early Research Award (Ontario). G. M., K. D. and É. D. have no conflicts of interest. G. M. and É. D. were involved in the conception of the study. G. M. and K. D. conducted the experiment. G. M. and É. D. analysed and interpreted the data. G. M. wrote the paper. É. D. and K. D. revised the manuscript.

\section{References}

1. Megel ME, Wade F, Hawkins P, et al. (1994) Health promotion, self-esteem, and weight among female college freshmen. Health Values 18, 10-19.

2. Racette SB, Deusinger SS, Strube MJ, Highstein GR \& Deusinger RH (2005) Weight changes, exercise, and dietary patterns during freshman and sophomore years of college. $J$ Am Coll Health 53, 245-251.

3. Hajhosseini L, Holmes T, Mohamadi P, Goudarzi V, McProud L \& Hollenbeck CB (2006) Changes in body weight, body composition and resting metabolic rate (RMR) in first-year university freshmen students. J Am Coll Nutr 25, 123-127.

4. Levitsky DA, Halbmaier CA \& Mrdjenovic G (2004) The freshman weight gain: a model for the study of the epidemic of obesity. Int J Obes Relat Metab Disord 28, 1435-1442.

5. Anderson DA, Shapiro JR \& Lundgren JD (2003) The freshman year of college as a critical period for weight gain: an initial evaluation. Eat Behav 4, 363-367.

6. Graham MA \& Jones AL (2002) Freshman 15: valid theory or harmful myth? J Am Coll Health 50, 171-173.

7. Hoffman DJ, Policastro P, Quick V \& Lee SK (2006) Changes in body weight and fat mass of men and women in the first year of college: a study of the 'freshman 15'. J Am Coll Health $\mathbf{5 5}$, $41-45$.

8. Morrow ML, Heesch KC, Dinger MK, Hull HR, Kneehans AW \& Fields DA (2006) Freshman 15: fact or fiction? Obesity 14, 1438-1443.

9. Douglas KA, Collins JL, Warren C, Kann L, Gold R, Clayton S, Ross JG \& Kolbe LJ (1997) Results from the 1995 National College Health Risk Behavior Survey. J Am Coll Health 46, $55-66$.

10. Leslie E, Fotheringham M, Veitch J \& Owen N (2000) A university campus physical activity promotion program. Health Promot J Aust 10, 51-54.

11. Leslie E, Owen N, Salmon J, Bauman A, Sallis JK \& Lo SK (1999) Insufficient active Australian college students: perceived personal, social and environmental influences. Prev Med 28, 20-27.

12. Stone G, Strikwerda-Brown J \& Gregg C (2002) Physical activity levels, sporting, recreational and cultural preferences of students and staff at a regional university campus. Aust Council Health, Phys Educ Recreation Healthy Lifestyles J 49, 39-43.

13. Wallace LS, Buckworth J, Kirby TE \& Sherman WM (2000) Characteristics of exercise behavior among college students: application of social cognitive theory to predicting stage of change. Prev Med 31, 494-505.

14. Butler SM, Black DR, Blue CL \& Gretebeck RJ (2004) Change in diet, physical activity, and body weight in female college freshman. Am J Health Behav 28, 24-32.

15. Matthews CE, Ainsworth BE, Thompson RW \& Bassett DR Jr (2002) Sources of variance in daily physical activity levels as measured by an accelerometer. Med Sci Sports Exerc 34, 1376-1381.

16. Brouten CV, Sauren AA, Verduin M \& Janssen JD (1997) Effects of placement and orientation of body-fixed accelerometers on the assessment of energy expenditure during walking. Med Biol Eng Comput 35, 50-56.

17. Stunkard AJ \& Messick S (1985) The three-factor eating questionnaire to measure dietary restraint, disinhibition and hunger. J Psychosom Res 29, 71-83.

18. Simmons JR, Smith GT \& Hill KK (2002) Validation of eating and dieting expectancy measures in two adolescent samples. Int J Eat Disord 31, 461-473.

19. Westenhoefer J, Stunkard AJ \& Pudel V (1992) Validation of the flexibile and rigid control dimensions of dietary restraint. Int $J$ Eat Disord 2, 53-64.

20. French SA, Harnack L \& Jeffery RW (2000) Fast food restaurant use among women in the Pound of Prevention study: dietary, behavioral and demographic correlates. Int J Obes Relat Metab Disord 24, 1353-1359.

21. Hovell MF, Mewborn CR, Randle Y \& Fowler-Johnson S (1985) Risk of excess weight gain in university women: a three-year community controlled analysis. Addic Behav 10, $15-28$.

22. American College Health Association (2006) American College Health Association National College Health Assessment (ACHA-NCHA) Spring 2005 Reference Group Data Report (abridged). J Am Coll Health 55, 5-16.

23. Gyurcsik NC, Spink KS, Bray SR, Chad K \& Kwan M (2006) An ecologically based examination of barriers to physical activity in students from grade seven through first-year university. J Adolesc Health 38, 704-711.

24. Lowry R, Galuska DA, Fulton JE, Wechsler H, Kann L \& Collins JL (2000) Physical activity, food choice, and weight management goals and practices among US college students. Am J Prev Med 18, 18-27.

25. Klesges RC, Isbell TR \& Klesges LM (1992) Relationship between dietary restraint, energy intake, physical activity, and 
body weight: a prospective analysis. J Abnorm Psychol 101, $668-674$

26. Mulvihill CB, Davies GJ \& Rogers PJ (2002) Dietary restraint in relation to nutrient intake, physical activity and iron status in adolescent females. J Hum Nutr Diet 15, 19-31.

27. National Institutes of Health (1998) Clinical Guidelines for the Identification, Evaluation and Treatment of Overweight and Obesity in Adults. Bethesda, MD: National Institutes of Health.

28. Simpson JA, MacInnis RJ, Peeters A, Hopper JL, Giles GG \& English DR (2007) A comparison of adiposity measures as predictors of all-cause mortality: the Melbourne collaborative cohort study. Obesity 15, 994-1003.
29. de Koning L, Merchant AT, Pogue J \& Anand SS (2007) Waist circumference and waist-to-hip ratio as predictors of cardiovascular events: meta-regression analysis of prospective studies. Eur Heart $J$ 28, 850-856.

30. Murgatroyd PR, Van De Ven ML, Goldberg GR \& Prentice AM (1996) Alcohol and the regulation of energy balance: overnight effects on diet-induced thermogenesis and fuel storage. $\mathrm{Br} \mathrm{J}$ Nutr 75, 33-45.

31. Suter PM \& Tremblay A (2005) Is alcohol consumption a risk factor for weight gain and obesity? Crit Rev Clin Lab Sci 42, $197-227$.

32. Horwath CC (1991) Dietary intake and nutritional status among university undergraduates. Nutr Res 11, 395-404. 